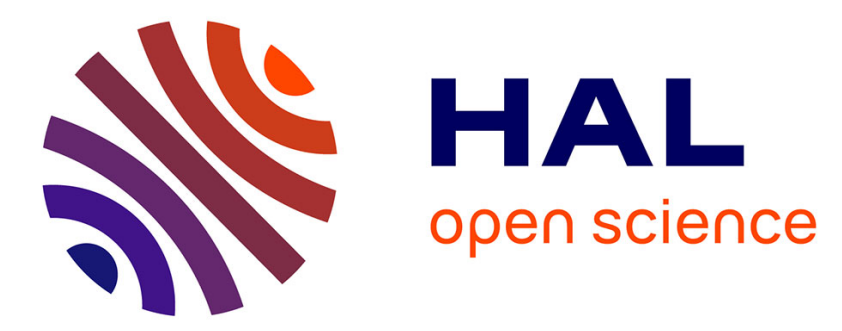

\title{
Multi-scale investigation of the effect of $\gamma$ irradiations on the mechanical properties of cementitious materials
}

Maxime Robira, Benoit Hilloulin, Ahmed Loukili, Gildas Potin, X. Bourbon, A. Abdelouas

\section{- To cite this version:}

Maxime Robira, Benoit Hilloulin, Ahmed Loukili, Gildas Potin, X. Bourbon, et al.. Multi-scale investigation of the effect of $\gamma$ irradiations on the mechanical properties of cementitious materials. Construction and Building Materials, 2018, 186, pp.484-494. 10.1016/j.conbuildmat.2018.07.038 . hal-02179742

\section{HAL Id: hal-02179742 \\ https://hal.science/hal-02179742}

Submitted on 11 Jul 2019

HAL is a multi-disciplinary open access archive for the deposit and dissemination of scientific research documents, whether they are published or not. The documents may come from teaching and research institutions in France or abroad, or from public or private research centers.
L'archive ouverte pluridisciplinaire HAL, est destinée au dépôt et à la diffusion de documents scientifiques de niveau recherche, publiés ou non, émanant des établissements d'enseignement et de recherche français ou étrangers, des laboratoires publics ou privés. 


\title{
Multi-scale investigation of the effect of $\gamma$ irradiations on the mechanical properties of cementitious materials
}

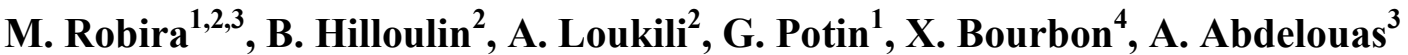 \\ ${ }^{1}$ Tractebel Engineering - Le Delage, 5 rue du 19 Mars 196292622 Gennevilliers CEDEX France \\ ${ }^{2}$ Laboratoire GeM - Ecole Centrale de Nantes, 1 rue de la Noë 44321 Nantes \\ ${ }^{3}$ Laboratoire SUBATECH - Ecole des Mines de Nantes, CNRS/IN2P3, Université de Nantes 4 rue Alfred \\ Kastler 44307 Nantes cedex 3 France \\ ${ }^{4}$ Agence nationale pour la gestion des déchets radioactifs - 1-7, Rue jean-Monnet - 92298 Chatenay- \\ Malabry Cedex
}

\section{Highlights}

- Mechanical properties of gamma irradiated mortar and cement paste were studied.

- Gamma irradiation induced Physico-chemical and mechanical modification of the uncarbonated cement materials.

- Water content influence the effect of gamma radiation on mechanical properties.

- Micro-indentation agrees with macroscopic observations. 
3

4

\section{ABSTRACT.}

We studied the effects of low doses of gamma radiations on physical and hydro-thermomechanical behavior of concrete in the context of radioactive wastes storage. Mortar samples were irradiated with a Cs-137 gamma source to perform three-points bending, compression and physical analysis. Dry, humid and carbonated mortars and dry and carbonated cement pastes were used. The structural and mineralogical modifications at microscopic scale due to irradiations are determined. The results show an important drop of mechanical strengths except in the case of carbonated samples. Thus, the hydrated phases of the mortar/cement are likely involved in the degradation of the mechanical properties.

KEY WORDS: Radioactive wastes, Microstructure, Mechanical properties, Creep, Image analysis, Gamma irradiation 


\section{Introduction}

Concrete is a multi-phases material often used as structural material for the storage and disposal of radioactive wastes [1][2]. As the structures are exposed to different types of radiation (mainly neutrons and gamma), it is essential to understand their effects of on concrete and determine the evolution of its mechanical properties after irradiation over longterm period.

Concrete behavior under radiations has long been studied mainly under neutron radiations in the case of nuclear power plants. For this radiation type, Hilsdorf [3] showed that the mechanical properties of concrete and particularly the strength characteristics may deteriorate because of nuclear radiations if the cumulated dose exceeds limiting values $\left(1.10^{19} \mathrm{n} / \mathrm{cm}^{2}\right)$. Some authors agreed that RIVE phenomenon (radiation induced volumetric expansion) is the predominant phenomenon which occurs in concrete after irradiation [4]. Kontani [5] suggests neutron or high dose rate gamma radiation effects are mainly concentrated at the level of hydrated and crystalline phases even though gamma radiations have a lesser impact on crystalline phases. Indeed, their effects mainly concern aggregates, suggesting that the variation of the concrete strength would be mainly created by cement paste intrinsic damages due to the volume variations of aggregates. The variation of the mechanical properties of concrete depends therefore on aggregates composition under neutronic radiation. Reviewing literature, Field [6] shows that whatever is the chemical composition of the aggregate type, a variation of the material strength appears only beyond specific threshold. This variation is also observed by Maruyama [7] under gamma radiations but for high doses (2.10 $\left.{ }^{8} \mathrm{~Gy}\right)$. Giorla [8] describes this strength variation as a result of three steps, an initial damage located in the aggregates/paste interface (ITZ), an increase of these damages as a result of the various applied constraints and a propagation of the damages through the paste. However, it is 
important to note that the variation of mechanical strength is highly dependent on the type of aggregates, studies having mainly been made on siliceous ones. Rosseel [9] describes these variations as a result of the thermal expansion of the aggregates and of the radiolysis drying of the paste. With their numerical model, Le Pape [10] and Maruyama go farther by explaining that the radiation effect occurs in $\mathrm{Si}-\mathrm{O}$ bonds situated in the $\mathrm{CSH}$ phases generating a modification of the porosity of the material. Hence, pre-existing damage before irradiations in the cement phases are aggravated by CSH degradation (modification of the organization of the CSH chains) and volumetric expansion of aggregates after irradiations.

However, it is important to note that these conclusions were drawn in the case of high-dose irradiation of cementitious materials, mainly in the case of neutronic radiation. Although some effects of gamma irradiations on cementitious materials have been described in the literature $[7][11][12]$, the degradation mechanisms and their mechanical impact are not well understood yet especially under low gamma irradiations where it is difficult to separate radiation effects and environmental effects. Most of the studies focused on physico-chemical evolutions, mainly because of radiolysis effects. Indeed, concrete is a material including an important part of water that could be affected by the radiations. Water radiolysis is a phenomenon that occurs under ionizing radiation (gamma radiation) and produces many species which can react with each other or with the environment to produce gases especially $\mathrm{H}_{2}$ [13]. Hydrogen production occurs mainly with the radiolysis of the free water present in macro porosity which can be composed by connected or unconnected pores [14]. Hence, $\mathrm{H}_{2}$ gas produced by water radiolysis can be evacuated in the case of connected pores but is trapped in the material in the case of unconnected pores. Bouniol [15][16] indicates that in a closed system saturated in gas, a gas/solution equilibrium occurs. Therefore, the $\mathrm{H}_{2}$ gas stays in solution and reacts with other radicals according to the Allen cycle, in particular in the smaller pores [17]. Indeed, if pore diameters are smaller than the radicals distribution area, 
then the radicals reactions with each other are increased. Hydrogen gas production in closed porosity can create constraints inside the material and generates cracks weakening the concrete. However, porosity can be directly impacted by atmospheric carbonation. Indeed, Groves and Kobayashi [18][19] showed carbonation deteriorate C-S-H and portlandite phases which are the main phases constituting cement paste. Pihlajavaara and Houst [20][21] described this deterioration as an important decrease of the material porosity impacting the mechanical strengths and the gases production.

The main objective of the present work is to accurately understand the effects of low dose gamma irradiation on the mechanical properties of cementitious materials. Such study, at the crossroads of mechanical and chemical engineering, appears to be important in the context of long-term nuclear waste storage. For this purpose, cementitious samples were irradiated under gamma irradiations with a dose rate of approximately $8 \mathrm{~Gy} / \mathrm{min}$. Mechanical properties, in particular compressive and bending strengths, were measured and compared to those measured on pristine samples in regards with physico-chemical evolutions at a smaller scale.

\section{Materials and methods}

\subsection{Sample conditioning and irradiation conditions}

Samples were prepared with CEM I 52.5 (ULTRACEM $52.5 \mathrm{~N}$ SR3PM) and 0/4 mm calcareous sand (INST. CRIB. LAV. BARVILLE) (table 1).

\section{Table 1. Mortar compositions}




\begin{tabular}{cccccc}
\hline Cement $\left(\mathrm{kg} / \mathrm{m}^{3}\right)$ & $\begin{array}{c}\text { Calcareous Sand 0/4 } \\
\left(\mathrm{kg} / \mathrm{m}^{3}\right)\end{array}$ & Water $\left(\mathrm{kg} / \mathrm{m}^{3}\right)$ & W/C & Paste volume (\%) & Air $\left(\mathrm{L} / \mathrm{m}^{3}\right)$ \\
\hline 566 & 1344 & 270 & 0.43 & 45 & 20 \\
\hline
\end{tabular}

114 No silica sand was used to avoid the high reactivity of silica under irradiations and possible

115 RIVE (Radiation Induced Volumetric Expansion). Organic additives like superplasticizer 116 were not used to prevent a premature degradation by irradiations. Indeed, organic species are

117 significantly affected by irradiations [22]. This formulation was determined to be as 118 representative as possible of a high-performance concrete used in nuclear waste storage 119 facility with a compressive strength close to $70 \mathrm{MPa}$ at 28 days. Three mortar series (dried, 120 carbonated and humid samples) and two cement paste series (dried and carbonated samples) 121 were prepared for irradiation experiments (tables 2 and 3 ). 
Table 2. Mortar samples description

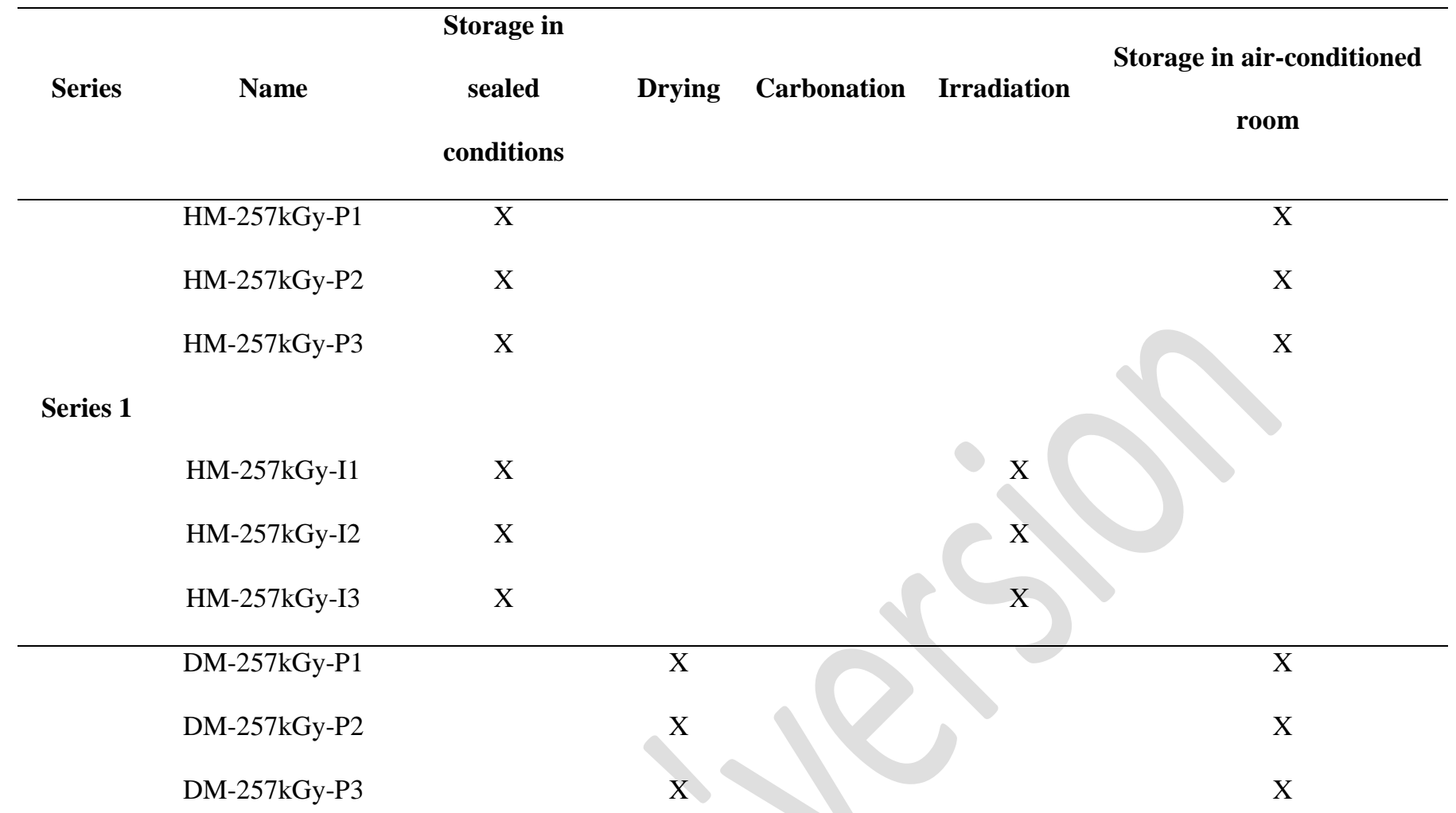

Series 2

\begin{tabular}{|c|c|c|c|c|}
\hline DM-257kGy-I1 & $\mathrm{X}$ & & $\mathrm{X}$ & \\
\hline DM-257kGy-I2 & $\mathrm{X}$ & & $X$ & \\
\hline DM-257kGy-I3 & $\mathrm{X}$ & & $X$ & \\
\hline CM-257kGy-P1 & $\mathrm{X}$ & $\mathrm{X}$ & & $\mathrm{X}$ \\
\hline CM-257kGy-P2 & $\mathrm{X}$ & $\mathrm{X}$ & & $\mathrm{X}$ \\
\hline CM-257kGy-P3 & $\mathrm{X}$ & X & & X \\
\hline
\end{tabular}

Series 3

$\begin{array}{lccc}\text { CM-257kGy-I1 } & \text { X } & \text { X } & \text { X } \\ \text { CM-257kGy-I2 } & \text { X } & \text { X } & \text { X } \\ \text { CM-257kGy-I3 } & \text { X } & \text { X } & \text { X }\end{array}$

124 
Table 3. Cement paste samples description

\begin{tabular}{|c|c|c|c|c|c|c|}
\hline Series & Name & $\begin{array}{l}\text { Storage in } \\
\text { sealed } \\
\text { conditions }\end{array}$ & Drying & Carbonation & Irradiation & $\begin{array}{l}\text { Storage in air- } \\
\text { conditioned room }\end{array}$ \\
\hline & DCP-85.7kGy-P1 & & $\mathrm{X}$ & & & $\mathrm{X}$ \\
\hline & DCP-85.7kGy-P2 & & $\mathrm{X}$ & & & $\mathrm{X}$ \\
\hline & DCP-85.7kGy-P3 & & $\mathrm{X}$ & & & $\mathrm{X}$ \\
\hline & DCP-85.7kGy-P4 & & $\mathrm{X}$ & & & $\mathrm{X}$ \\
\hline Series 1 & DCP-85.7kGy-P5 & & $\mathrm{X}$ & & & $\mathrm{X}$ \\
\hline & DCP-85.7kGy-I1 & & $\mathrm{X}$ & & & \\
\hline & DCP-85.7kGy-I2 & & $\mathrm{X}$ & & $\mathrm{X}$ & \\
\hline & DCP-85.7kGy-I3 & & $\mathrm{X}$ & & $\mathrm{X}$ & \\
\hline \multirow{6}{*}{ Series 2} & CCP-85.7kGy-P1 & & $X$ & $\mathrm{X}$ & & $\mathrm{X}$ \\
\hline & CCP-85.7kGy-P2 & & $\mathrm{X}$ & $X$ & & $\mathrm{X}$ \\
\hline & CCP-85.7kGy-P3 & & $X$ & $\mathrm{X}$ & & $\mathrm{X}$ \\
\hline & CCP-85.7kGy-I1 & & $\mathrm{X}$ & $\mathrm{X}$ & $\mathrm{X}$ & \\
\hline & CCP-85.7kGy-I2 & & $\mathrm{X}$ & $\mathrm{X}$ & $\mathrm{X}$ & \\
\hline & CCP-85.7kGy-I3 & & $\mathrm{X}$ & $\mathrm{X}$ & $\mathrm{X}$ & \\
\hline
\end{tabular}

127

128 Samples names are composed by the sample type (HM : humid mortar, DM : dried mortar,

$129 \mathrm{CM}$ : carbonated mortar, DCP : dried cement paste, CCP: carbonated cement paste), the value 130 of the cumulated radiation dose (257 kGy for mortar and $85.7 \mathrm{kGy}$ for cement paste) and the 131 treatment type (P : pristine for unirradiated samples and I : for irradiated samples). The 132 different cycles of preparation are detailed in figure 1. 


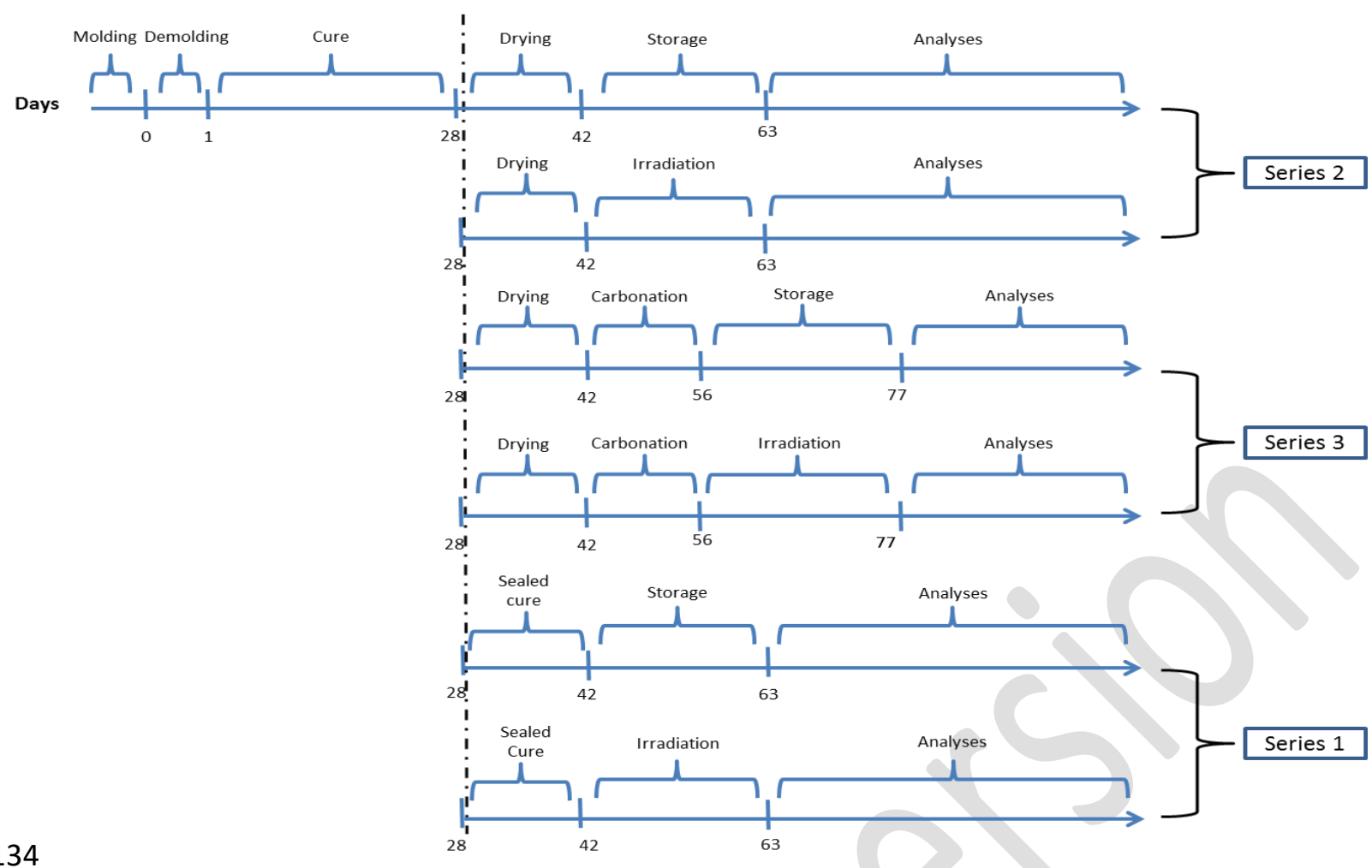

135 Fig.1. Preparation cycles of the different series studied.

137 Mortar and cement paste prisms, with dimensions of $4 \times 4 \times 16 \mathrm{~cm}^{3}$, were casted in peek 138 molds to avoid any metallic contamination due to the mold. After one day of curing under 139 sealed and ambient conditions $\left(20^{\circ} \mathrm{C}\right.$ and $90 \%$ relative humidity - $\left.\mathrm{RH}\right)$, samples were 140 demolded. They were then cured in lime-saturated water for 28 days. Then, the first series 141 (series 1) was stored in sealed conditions for 14 days. The prisms were covered by aluminum 142 foil, placed in airtight plastic bags and stored in ambient conditions. The other two series 143 (series 2 and 3) were dried during 14 days in a ventilated oven at $45{ }^{\circ} \mathrm{C}$ to not degrade the 144 ettringite phase $\left(\mathrm{Ca}_{6} \mathrm{Al}_{2}(\mathrm{SO} 4)_{3}(\mathrm{OH})_{12} \cdot 26 \mathrm{H}_{2} \mathrm{O}\right)$ (a constant mass was measured after 10 days). 145 After drying, one of the two (series 3) was carbonated in a $\mathrm{CO}_{2}$-rich atmosphere at $50 \%$ of $146 \mathrm{CO}_{2}$ and $63 \% \mathrm{RH}$ [23]. Samples were almost completely carbonated after 13 days (figure 2). 

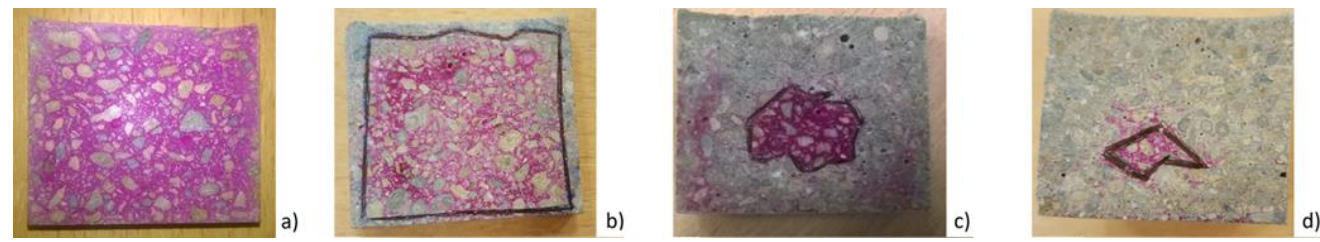

149 Fig.2. Evolution of the carbonation after 0 a), 1d b), 5d c) and 13 d) days. Carbonated zone in grey and 150 pristine zone in purple discriminated using a phenolphthalein solution.

A phenolphthalein test was performed on all samples to confirm the non-carbonation and the carbonation of the different mortar series (figure 3 and 4). Except for the carbonated series no carbonation was noticed.
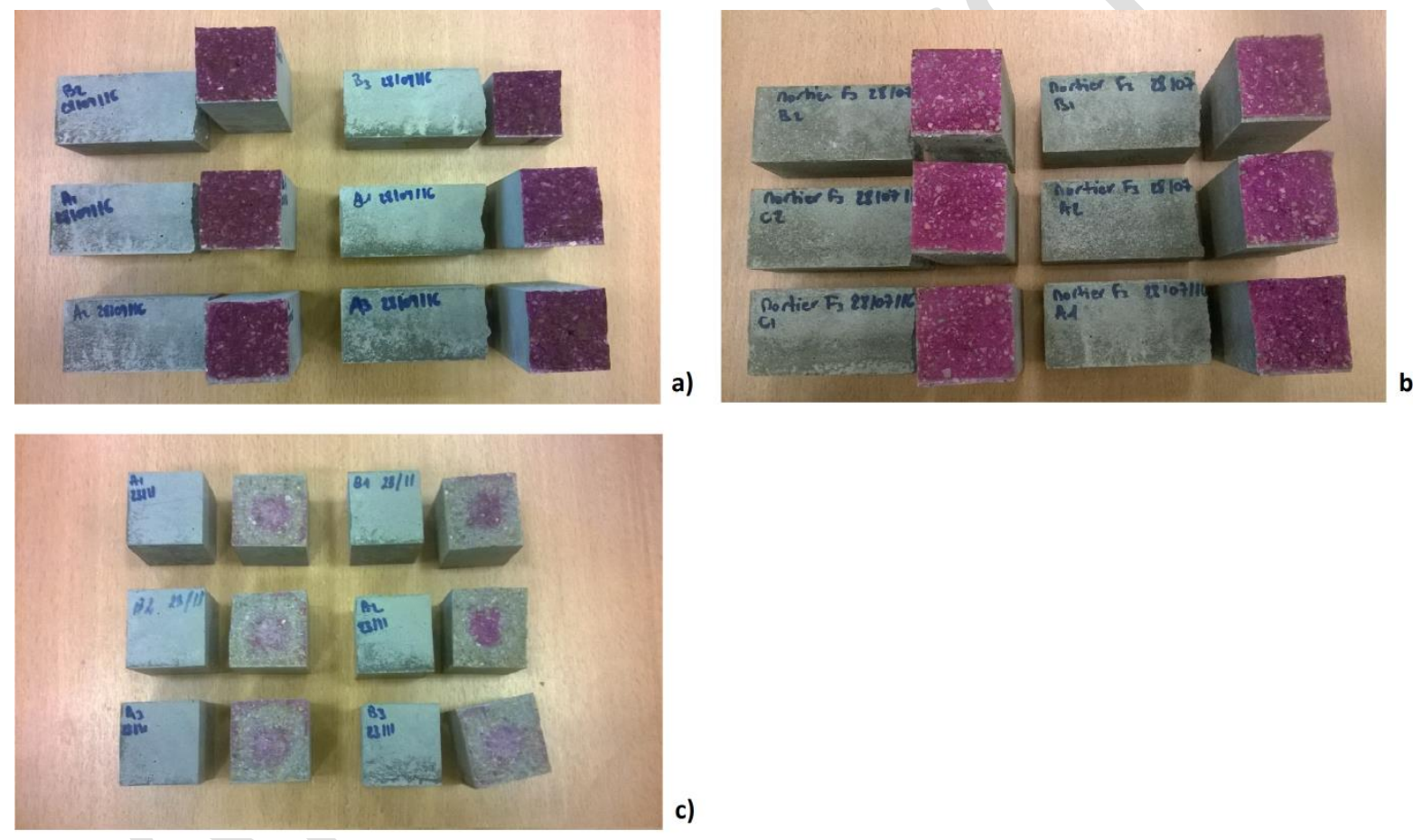

Fig.3. Phenolphthalein test on humid mortar a), dried mortar b) and carbonated mortar c). 


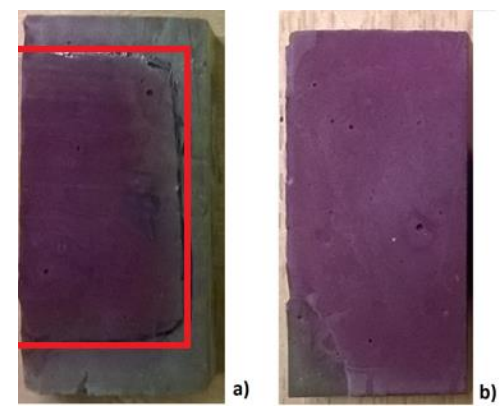

160 Fig.4. Phenolphthalein test on an half part of a carbonated cement paste slice a) and dried cement paste slice b) with carbonation front in red line.

For each series, half of the samples were exposed to $\gamma$ irradiations in an irradiator with a ${ }^{137} \mathrm{Cs}$

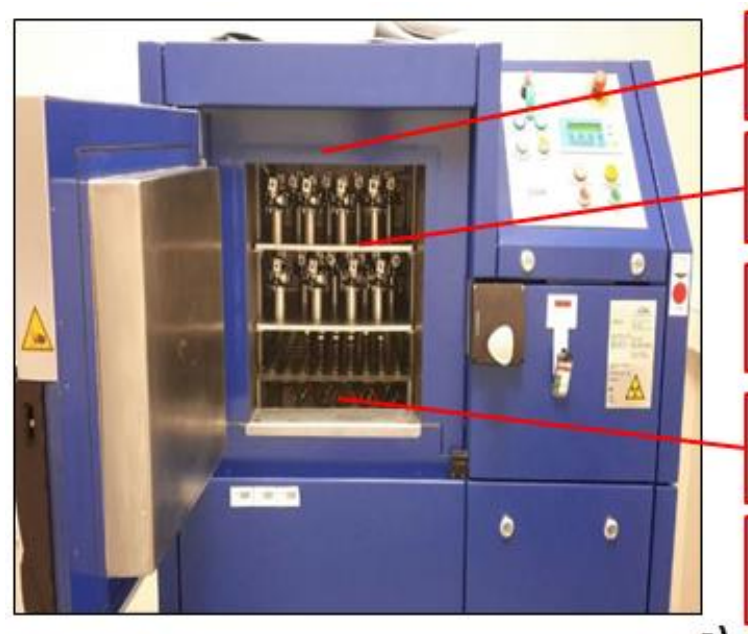

a)

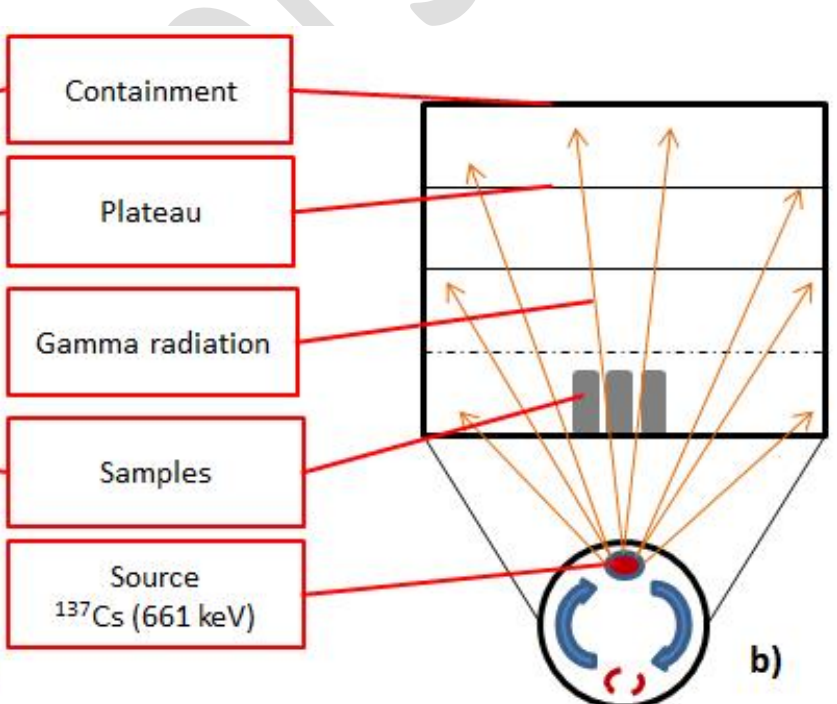

Fig.5. Picture of gamma irradiator a) and schematic representation b).

The total $\gamma$ dose received by the specimens was estimated to be around $257 \mathrm{kGy}(85.7 \mathrm{kGy}$ in

the case of cement pastes). It was based on a map of the different dose rate realized by Fricke dosimetry measurement [24]. The other half of the samples was stored in ambient conditions near the gamma irradiator during the irradiation duration. They were used as references and compared with the irradiated samples (used to standardized measures). After each step, the weight samples were monitored to dissociate the direct influence of the irradiation (radiolysis 
175 phenomenon) from an eventual drying phenomenon due to irradiations. Mass variations of the 176 mortar prisms are shown in figure 6.

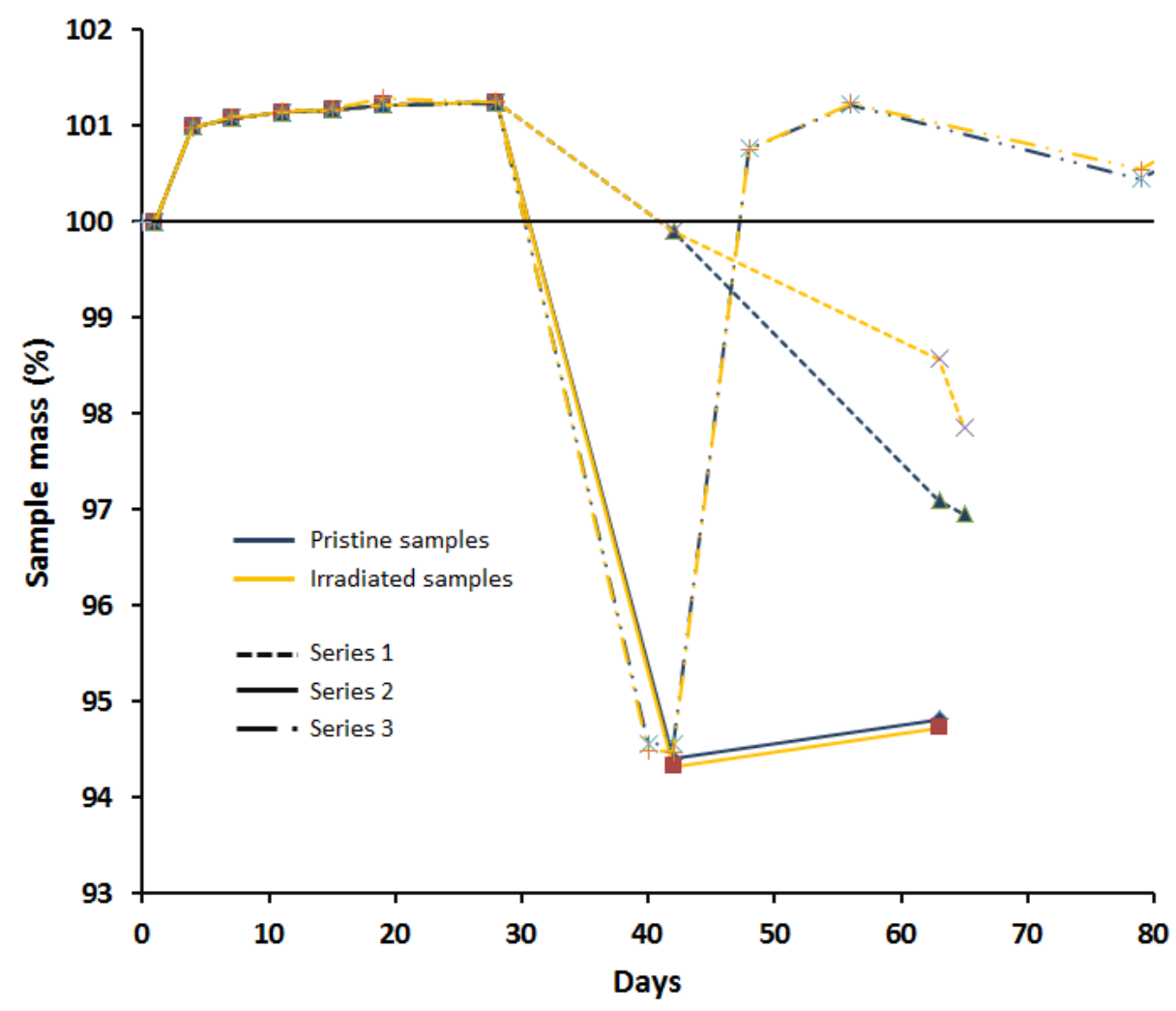

177

178 Fig.6. Monitoring of the mass evolution of mortar samples with $100 \%$ corresponding to the mass of mortar pouring. Black straight line corresponding to the initial mass measured after the demolding phase at $24 \mathrm{~h}$.

\subsection{Multiscale analysis}

185 After the irradiation step, a crack-mouth opening displacement (CMOD) control three-point bending test was performed. The sample was centered on top of two $10 \mathrm{~cm}$-distant holders and a force was applied in its center. Small $1 \mathrm{~mm}$ wide and $2 \mathrm{~mm}$ depth notches were sawn on the face closer to the radiation source of the specimens to initiate cracking from the notch tip. 
The force was regulated to ensure a CMOD opening rate of $0.1 \mu \mathrm{m} / \mathrm{s}$ up to $40 \mu \mathrm{m}$ before unloading. An unloading stage was performed on the softening part of the curve and then, the specimens were reloaded until a CMOD corresponding to a residual load of around $0.2 \mathrm{kN}$. An example of a typical standard curve is shown in figure 7.

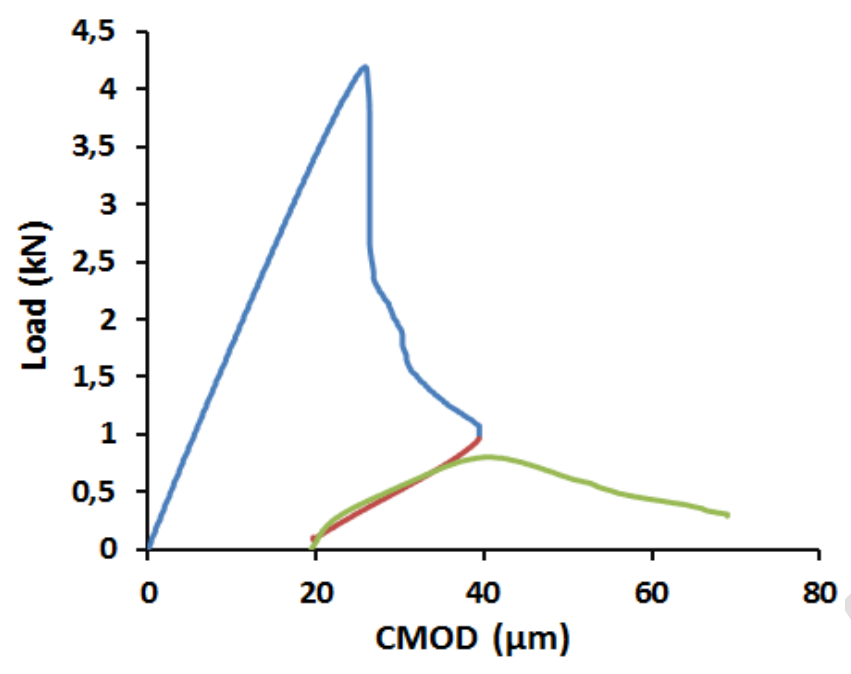

Fig. 7. Typical three-point bending curve obtained on mortar sample (MD-257kGy-P2).

\section{Compression tests}

197 After the three-points bending analysis, two $4 \times 4 \times 4 \mathrm{~cm}^{3}$ cubes were sawn from the residual parts of each prism aside from the central crack. Compression analyses were performed on a 199 press MTS $500 \mathrm{kN}$. Each cube was placed on a $4 \times 4 \mathrm{~cm}^{2}$ base. A force with a load rate of $2.4 \mathrm{kN} / \mathrm{sec}$ was applied until the specimen break to measure the compressive strength. 
203 Water and Mercury Intrusion Porosimetry (MIP) tests were performed on slices of the specimens [25]. For water porosimetry, a slice of $2 \times 4 \times 4 \mathrm{~cm}^{3}$ was used. Three masses were measured:

- $\quad \mathrm{m} 1=$ mass of the dried sample,

- $\mathrm{m} 2=$ mass of the sample immersed in water,

- $\quad \mathrm{m} 3=$ mass of the water-saturated sample.

Open porosity was calculated with the following equation:

$$
\pi=100 \times \frac{m 3-m 1}{m 3-m 2}
$$

This method is used to measure the total open pores volume. To know the repartition of the porosity, specimens were analyzed with mercury intrusion. Mercury porosimetry analysis is a progressive intrusion of mercury into a porous structure under stringently controlled pressures using a Micromeritics AutoPore IV-9500 device. Small cubic specimens, with $1 \times 1 \times 1 \mathrm{~cm}^{3}$ dimensions were cut and placed in a penetrometer where a partial vacuum $(70 \mu \mathrm{mHg})$ is established. Analysis consist in two step, one on applying a pressure of 30 psi by injecting mercury through the capillary tube with nitrogen and the second on applying a high-pressure (60 kpsi).

From the pressure versus intrusion data, the instrument generates volume and size distributions in the material for sizes going of $5 \mathrm{~nm}$ to several hundred micrometer by using the Washburn equation [26]:

$$
\text { d.P }=-4 \gamma \cos \theta
$$

with $\mathrm{d}$ : pore diameter, $\mathrm{P}:$ mercury intrusion pressure, $\gamma:$ surface tension, $\theta:$ liquid solid angle. 
Micro-indentation testing is a method for measuring elastic and creep parameters of a material at a microscopic scale. A precision diamond indenter is impressed into the material at a specific load. The imprint depth and the test load are used to calculate a hardness value while the unloading curve leads to the indentation modulus determination. Micro-indentation tests were performed on a volume of $2 \times 2 \times 1.5 \mathrm{~cm}^{3}$ from the middle part of a half of the $4 \times 4 \times 16 \mathrm{~cm}^{3}$ after the three-point bending test. The aim was to select a location to avoid damage induced by the three-point bending test. Micro-indentation was performed using a Vickers indenter probe over a grid of $20 \times 20$ indents spaced by $500 \mu \mathrm{m}$ with a $2000 \mathrm{mN}$ force to investigate a representative surface of $1 \times 1 \mathrm{~cm}^{2}$ of the mortar sample. Indentation runs were performed under similar relative humidity conditions to avoid the influence of the relative humidity on creep parameters. After measurement, cement paste properties were extracted using hierarchical clustering and then further refined using a method combining the deconvolution of the indentation tests and a 3D microscope image analysis. This method is described in a dedicated paper [27].

\section{$\underline{\text { ATR analysis }}$}

Attenuated total reflection (ATR) is a qualitative technique used in conjunction with infrared spectrometry to measure the changes occurring in a totally internally reflected infrared beam when the beam comes into contact with a sample. Samples can be examined in the solid or liquid without preparation. ATR is a surface analysis which can determine the different phases which constitute a sample. A $1 \times 1 \times 1 \mathrm{~cm}^{3}$ cube was cut in the center of the prism and analyzed with ATR to estimate the evolution of the different phases after irradiations. Tests were performed on Bruker Tensor 27 analyzer. 16 scans per sample were realized between 
$600 \mathrm{~cm}^{-1}$ and $4000 \mathrm{~cm}^{-1}$ with a $4 \mathrm{~cm}^{-1}$ resolution under ambient atmosphere. Sequences of 16 scans were repeated three times on three random areas and averaged.

\section{Results and discussion}

\subsection{Mechanical results on cement paste}

Compressive and bending strength were determined on cement paste samples. Raw results are shown in table 4. Standardized strengths are then calculated. The mean of irradiateduncarbonated (DCP-85.7kGy-I1 to DCP-85.7kGy-I3) and irradiated-carbonated (CCP85.7kGy-I1 to CCP-85.7kGy-I3) samples are normalized in regards with respectively the mean of unirradiated-uncarbonated (DCP-85.7kGy-P1 to DCP-85.7kGy-P5) and unirradiatedcarbonated (CCP-85.7kGy-P1 to CCP-85.7kGy-P3) samples (figure 8).

A trend can be extracted showing a decrease of mechanical strengths for all samples. Indeed, a decrease of the compressive strength by $3.6 \%$ between unirradiated and irradiated pristine samples, and a $13 \%$ decrease between unirradiated and irradiated carbonated sample can be observed after a total dose of $85.7 \mathrm{kGy}$. Similarly, a decrease by $18 \%$ and $3.6 \%$ can be observed concerning the bending strength. However, the dispersion of the data (around $10 \%$ of standard deviation) does not lead to any statistical difference (t-test $<1 \%$ ). ATG analyses were performed on irradiated and pristine uncarbonated samples and no carbonation was observed [28]. To confirm this trend, experiments were reiterated on mortars as described in part 2.1. 
272 Table 4. Cement paste mechanical strength results with the standard deviation

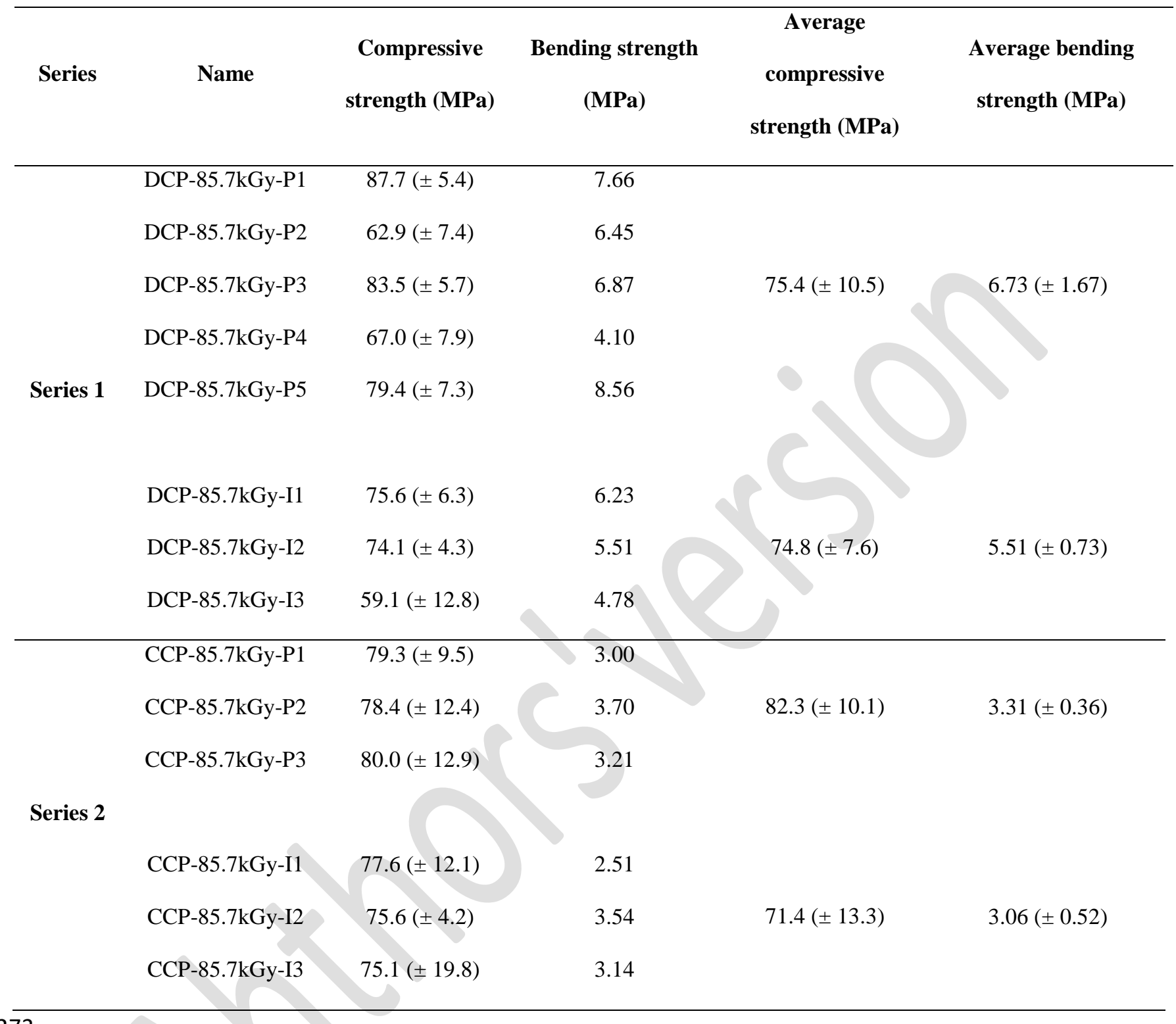

273

274 

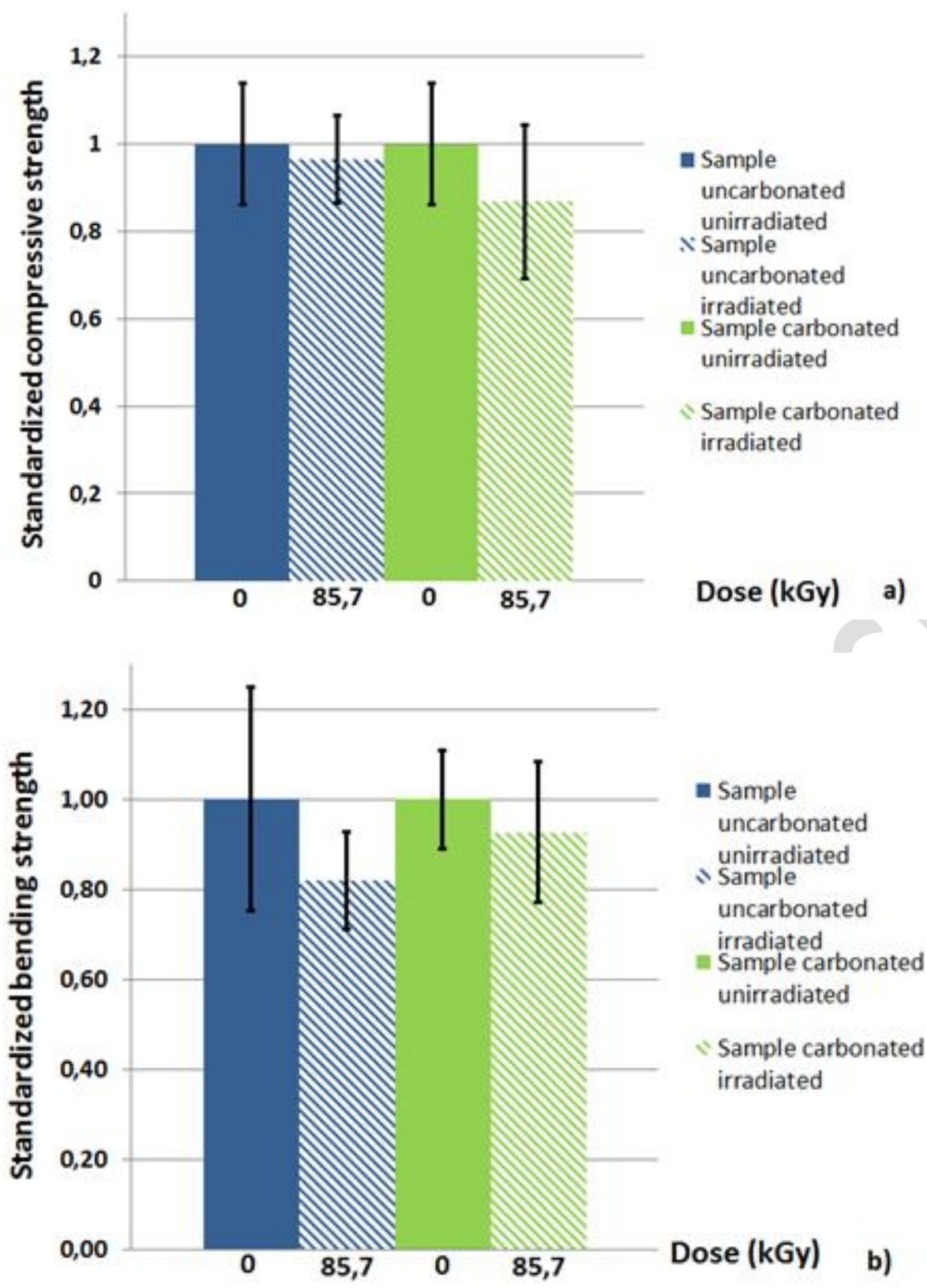

278 Fig. 8. Standardized compressive strengths a) and bending strengths b) and standard deviations for 279 cement paste, uncarbonated (blue) and carbonated (green), unirradiated and irradiated in regards with 280 the mean of unirradiated samples. 


\subsection{Mechanical results on mortars}

Compressive and bending strength were measured for all mortar samples. Raw results are summarized in table 5 and standardized values are plotted in figure 9.

A significant (t-test $<1 \%$ ) 4\% (resp. 9\%) decrease of the compressive strength and a $15 \%$ (resp. $20 \%$ ) drop of the bending strength were measured on the humid samples (resp. dried samples) after a total dose of $257 \mathrm{kGy}$ (figure 9). For the carbonated samples, no significant decrease of the compressive or bending strength was noticed (t-test $>80 \%$ ). Carbonation is a phenomenon which induces portlandite transformation into calcite. Thus, after carbonation calcite is a dominant phase in our sample. Irradiations don't seem to have mechanical 292 influence on calcite phase. Calcite is a phase studied under irradiations for a long time. This 293 observation is in accordance with the literature where authors agree to say gamma irradiation doesn't have any effect on calcite [29][30]. Consequently, the decrease of the compressive and bending strength observed for humid and dried samples cannot be related to macroscopic degradation of the sand phase (99.9\% calcareous sand used for the mortar formulation) and 297 calcite phase obtained by natural carbonation during irradiation time. 
Table 5. Mortar mechanical strength results with the standard deviation

\begin{tabular}{|c|c|c|c|c|c|}
\hline \multirow[b]{2}{*}{ Series } & \multirow[b]{2}{*}{ Name } & \multicolumn{4}{|c|}{ Average } \\
\hline & & $\begin{array}{c}\text { Compressive } \\
\text { strength (MPa) }\end{array}$ & $\begin{array}{c}\text { Bending } \\
\text { strength (MPa) }\end{array}$ & $\begin{array}{c}\text { compressive } \\
\text { strength (MPa) }\end{array}$ & $\begin{array}{l}\text { Average bending } \\
\text { strength (MPa) }\end{array}$ \\
\hline & HM-257kGy-P1 & $82.9( \pm 0.7)$ & 7.13 & & \\
\hline & HM-257kGy-P2 & $83.3( \pm 0.4)$ & 7.27 & $83.0( \pm 0.5)$ & $7.60( \pm 0.70)$ \\
\hline & HM-257kGy-P3 & $82.8( \pm 0.2)$ & 8.41 & & \\
\hline
\end{tabular}

Series 1

\begin{tabular}{lllll} 
HM-257kGy-I1 & $80.6( \pm 0.8)$ & 6.54 & & \\
HM-257kGy-I2 & $79.3( \pm 0.3)$ & 6.94 & $5.2( \pm 0.9)$ & $6.47( \pm 0.51)$ \\
HM-257kGy-I3 & $80.9( \pm 0.1)$ & 5.93 & \\
\hline DM-257kGy-P1 & $67.7( \pm 0.1)$ & 10.15 & & \\
DM-257kGy-P2 & $69.6( \pm 2.5)$ & 10.22 & $69.1( \pm 1.6)$ & $10.10( \pm 0.15)$ \\
DM-257kGy-P3 & $69.2( \pm 0.1)$ & 9.94 &
\end{tabular}

Series 2

\begin{tabular}{lllll} 
DM-257kGy-I1 & $63.3( \pm 0.1)$ & 8.48 & & \\
DM-257kGy-I2 & $62.8( \pm 0.8)$ & 8.09 & $63.0( \pm 0.5)$ & $8.10( \pm 0.37)$ \\
DM-257kGy-I3 & $62.8( \pm 0.1)$ & 7.73 & \\
\hline CM-257kGy-P1 & $115.7( \pm 0.9)$ & 5.23 & & \\
CM-257kGy-P2 & $113.7( \pm 0.5)$ & 5.95 & $114.9( \pm 1.4)$ & $5.91( \pm 0.66)$ \\
CM-257kGy-P3 & $115.4( \pm 1.9)$ & 6.54 & &
\end{tabular}

Series 3

$\begin{array}{lllll}\text { CM-257kGy-I1 } & 112.8( \pm 1.1) & 6.26 & & \\ \text { CM-257kGy-I2 } & 115.4( \pm 0.1) & 5.56 & 114.7( \pm 1.8) & 5.59( \pm 0.64) \\ \text { CM-257kGy-I3 } & 116.2( \pm 0.3) & 4.97 & \end{array}$

300

301

302 

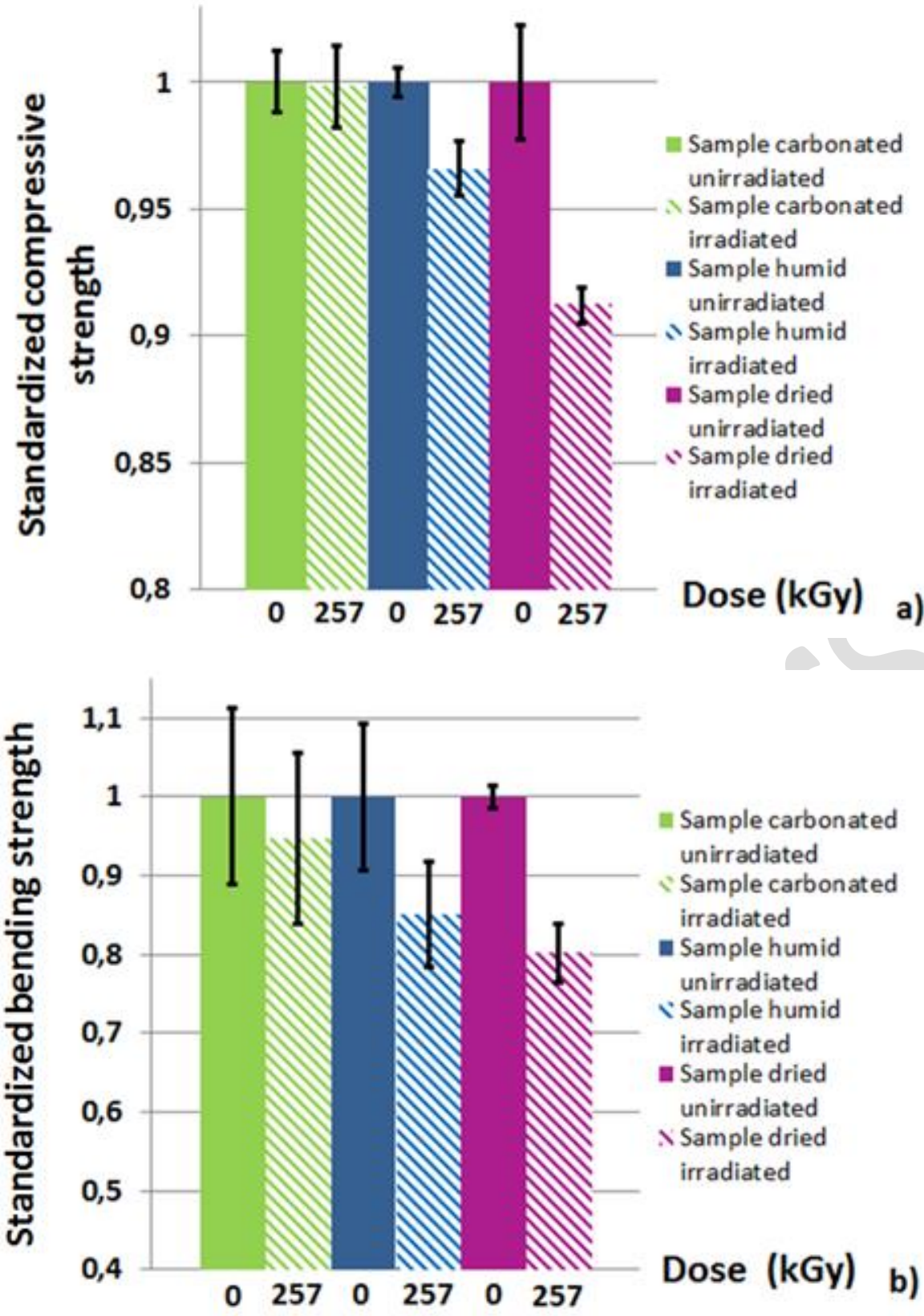

Fig. 9. Standardized compressive strengths a) and bending strengths b) and standard deviation for mortar dried (violet), humid (blue) and carbonated (green), unirradiated and irradiated in regards with the mean of unirradiated samples.

311 Furthermore, the quantity of free water, present in the sample, seems to influence the degradation by gamma radiations as mechanicals losses are smaller for the humid samples than for the dried samples. It seems that free water attenuates the degradations by gamma 
radiations. Quantity of free water and mechanical properties are directly affected by the porosity [31][32][33]. Water immersion porosimetry analysis shows that the total open porosity is similar before and after irradiations for all of the three series ( $20 \%$ for series 1 and 2 and $13 \%$ for series 3). However, even if total pore volume stays unchanged, its distribution evolves after irradiation (figure 10). Mercury porosimetry analyses reveal a decrease of the median pore diameter except for carbonated prisms. Indeed, in the case of dried samples, the reduction of median pore diameter $(9.9 \mathrm{~nm}$ to $8.2 \mathrm{~nm})$ is greater than the decrease observed for humid prisms $(5.9 \mathrm{~nm}$ to $5.5 \mathrm{~nm})$. Likewise, calcite phase seems to protect the samples against gamma radiations (no variation of median pore diameter). A correlation appears between porosity evolution and compressive strength decrease as illustrated in figure 11 . This relation may indicate an influence of the nanoporosity evolution on the macroscopic strength evolution of the mortars while their relation is not clear to the authors.

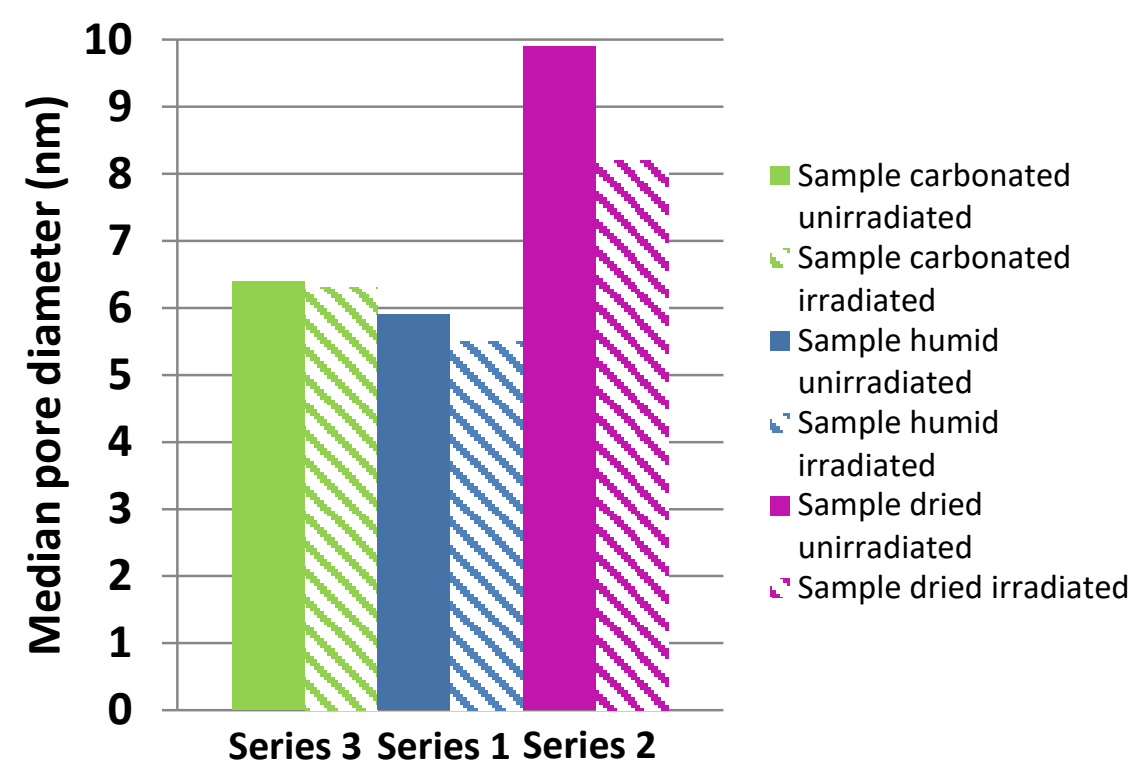

Fig. 10. Comparison of median pore diameters of carbonated (green), humid (blue) and dried (violet) unirradiated and irradiated mortar. 


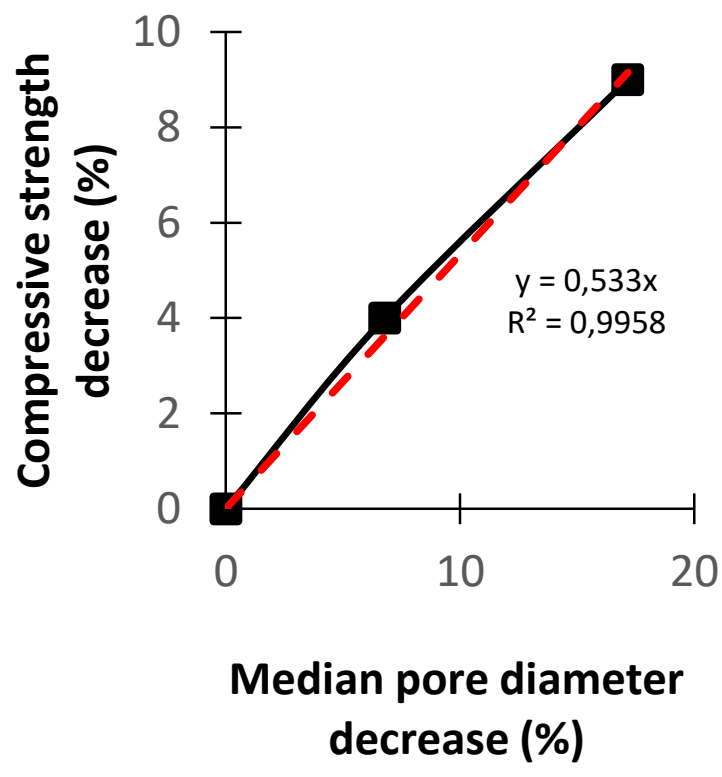

332 Fig. 11. Relation between porosity decrease and compressive strength decrease due to irradiations on 333 the three different mortar series.

335 Porosity modification is usually assigned to chemical changes. It does not seem to be the case 336 in our samples as ATR analysis shows no phase change before and after irradiations (figure 337 12). Indeed, the wavenumber associated with every peak does not change for all samples. 338 Furthermore, ATR is not a quantitative method; the intensity of peaks may not be 339 representative of the quantity of a phase present in sample. Moreover, X-ray analyses were 340 performed on mortar samples and none crystallographic changes were observed for all series 341 (an example of X-ray diffractogram of dried mortar is given in figure 13). 


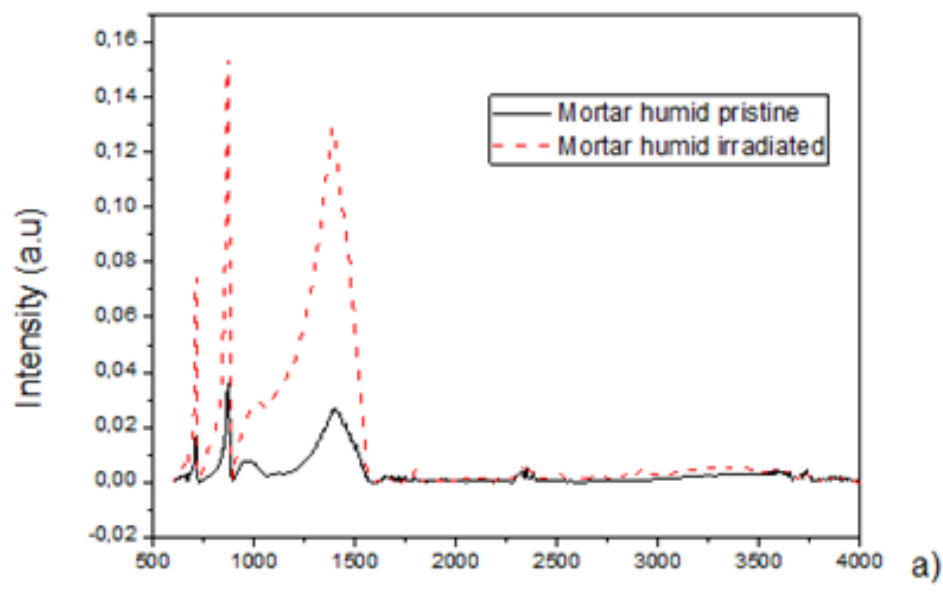

343

Wavenumber $\left(\mathrm{cm}^{-1}\right)$

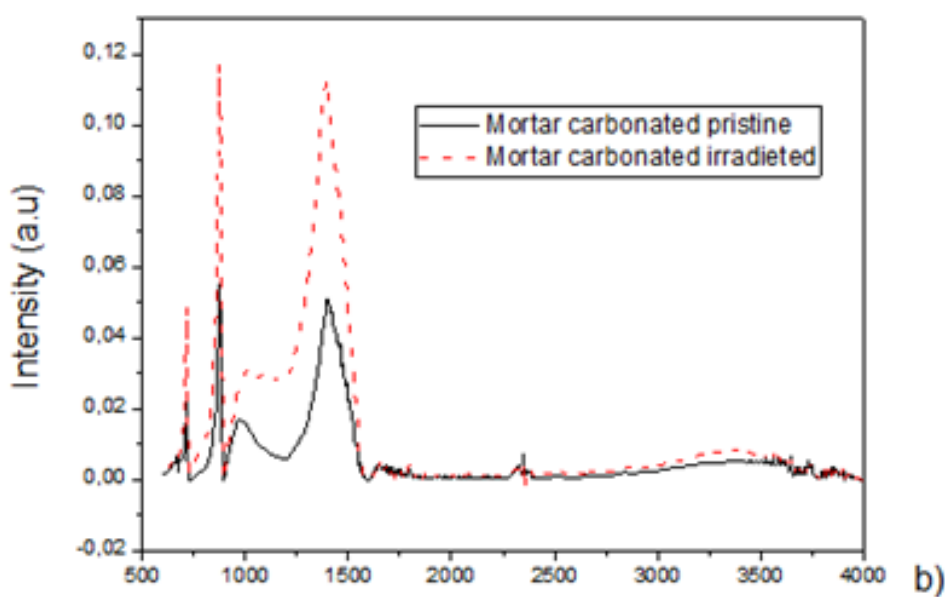

Wavenumber $\left(\mathrm{cm}^{-1}\right)$

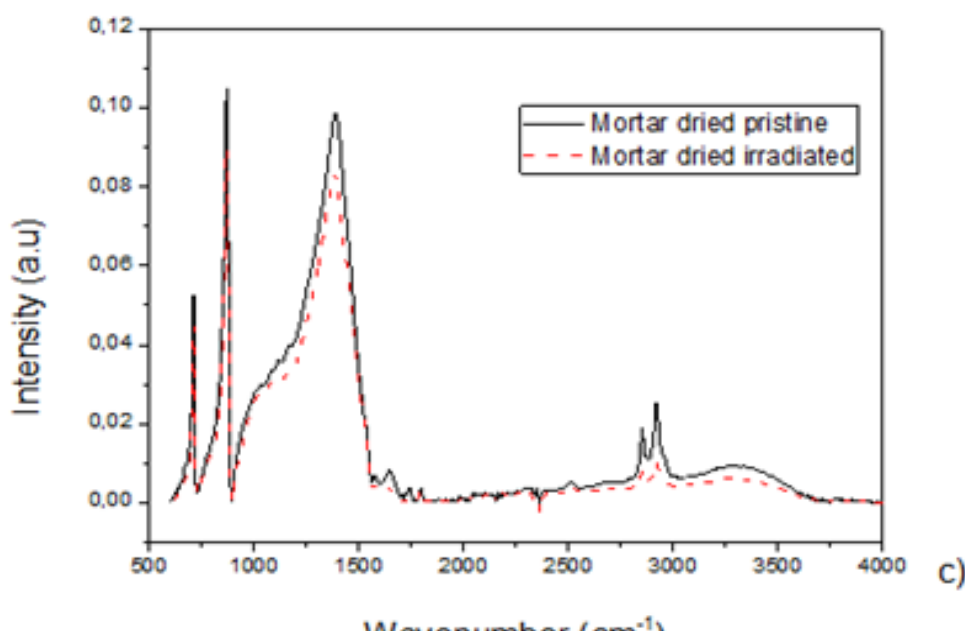

Wavenumber $\left(\mathrm{cm}^{-1}\right)$

346 Fig. 12. ATR spectrum of a) humid, b) carbonated and c) dried mortars both unirradiated (solid line)

347 and irradiated (broken line). 


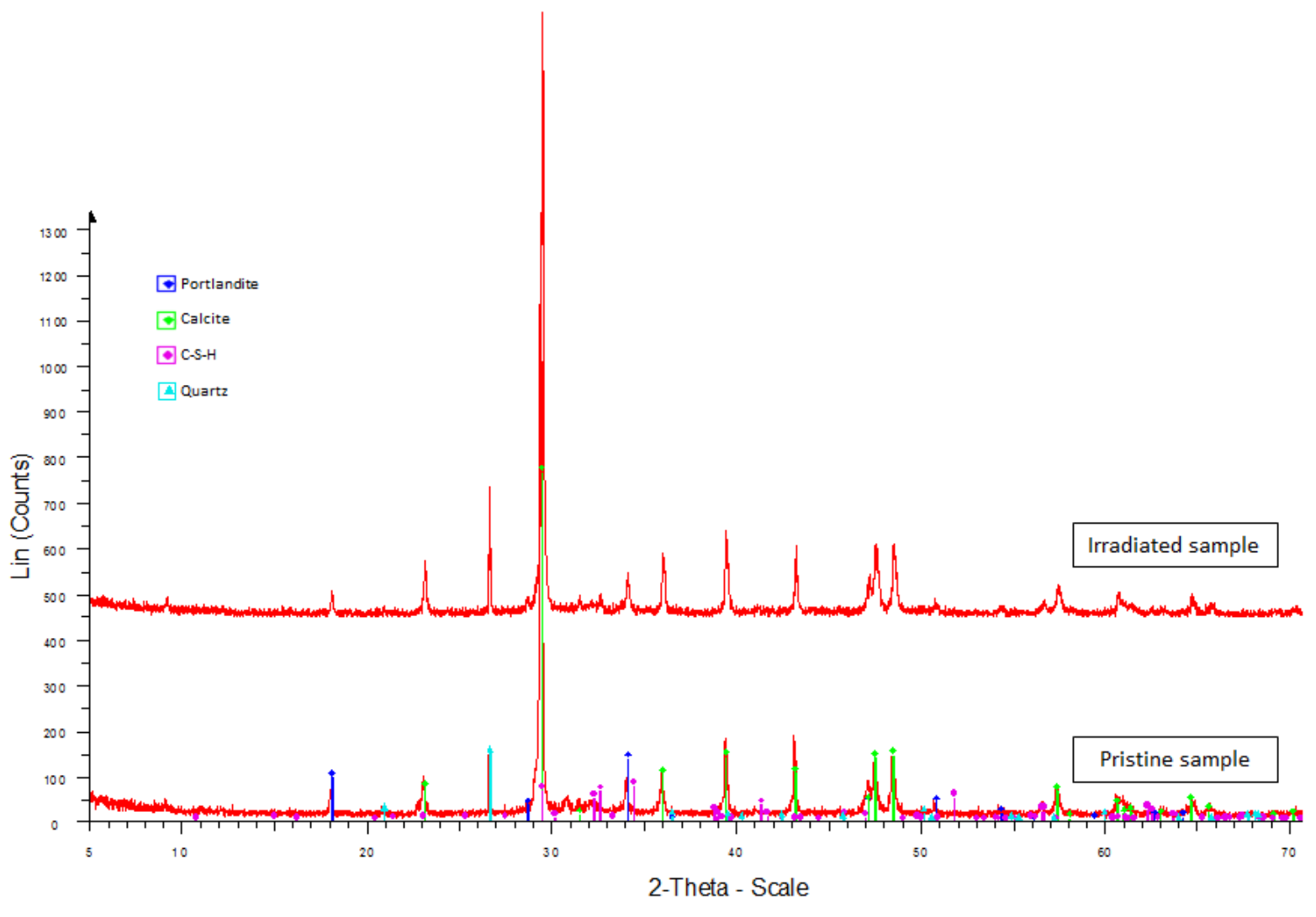

Fig. 13. X-ray diffractrogram of irradiated and pristine dried mortar.

Micro-indentation results give some first insights on the evolutions of the multi-scale behavior of the irradiated mortars. Cement paste properties were successfully extracted from the statistical indentation performed on the mortars using the complementarity between numerical clustering and 3D imaging as exposed in an article from the authors [27]. The obtained distributions associated with the various variables characterizing the cement paste are mostly well-defined and normal-like which allows for a fast and accurate comparison. As illustrated in figure 14 a), a significant increase of the dried and humid mortars hardness can be observed. Indeed, unirradiated dried mortars have a median hardness of $388 \mathrm{MPa}$ while the median hardness of irradiated corresponding series is increased by around 7.2\% (416 Mpa). Humid specimens exhibit the same evolution as the median hardness of irradiated specimens is around $3.5 \%$ higher (346 MPa vs $334 \mathrm{MPa}$ ) than the one of unirradiated specimens. This increase of the specimens' hardness due to $\gamma$-radiations may be correlated with their strength. 
364 On the other hand, similarly to the macroscopic observations, no significant micromechanical

365 evolution of the carbonated mortars was noticed $(+1 \%)$.

366 Creep parameters are affected similarly: indentation creep modulus of dried and humid

367 mortars regarding the median reference values are respectively increased by $13.7 \%$ and $7.1 \%$

368 meaning that these two mortars creep less than the pristine reference samples. Their creep

369 characteristic time decreases, $-9.8 \%$ for the dried specimens and $-6.1 \%$ for the humid

370 specimens, which means that their long-term logarithmic behavior is attained after a short

371 period of time.

372 Creep parameters of the carbonated specimens are not affected much: indentation creep 373 modulus does not significantly evolve (-1.4\%) and creep characteristic time increases 374 slightly by $5.5 \%$. 


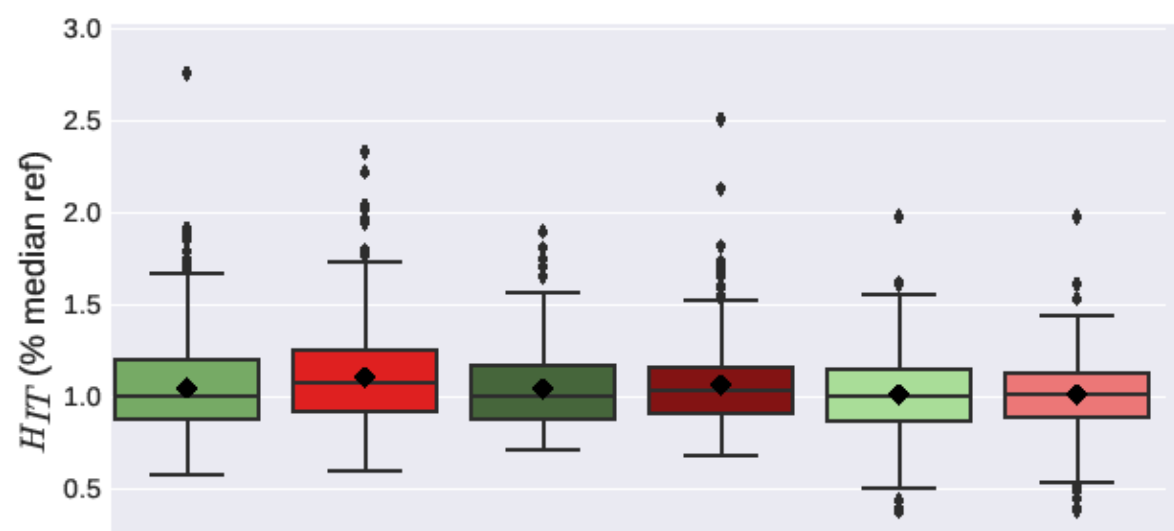

0.0 MD-257kGy-P MD-257kGy-I MH-257kGy-P MH-257kGy-I MC-257kGy-P MC-257kGy-I Specimen

a)

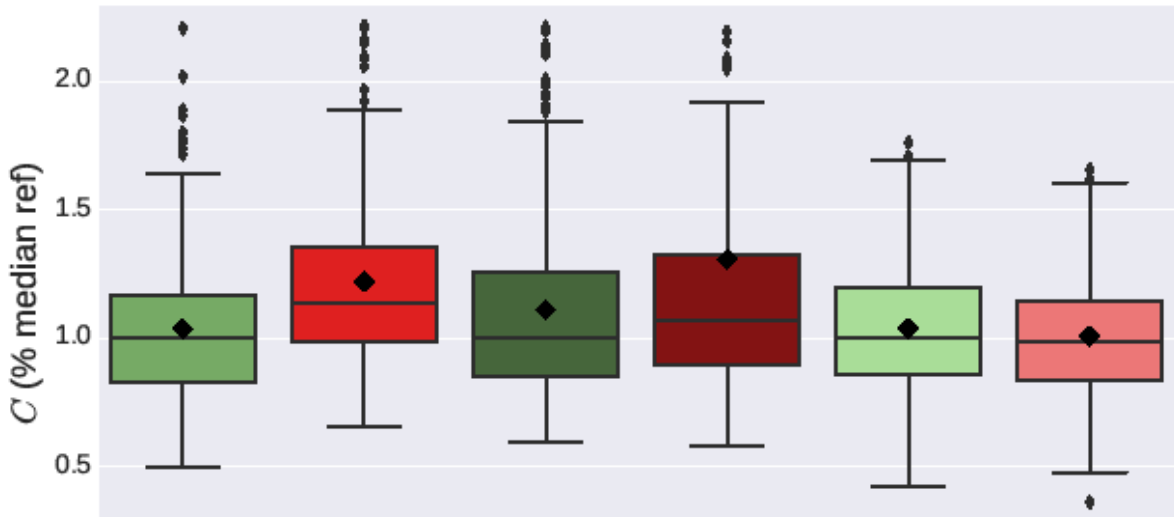

MD-257kGy-P MD-257kGy-I MH-257kGy-P MH-257kGy-I MC-257kGy-P MC-257kGy-I Specimen

b)

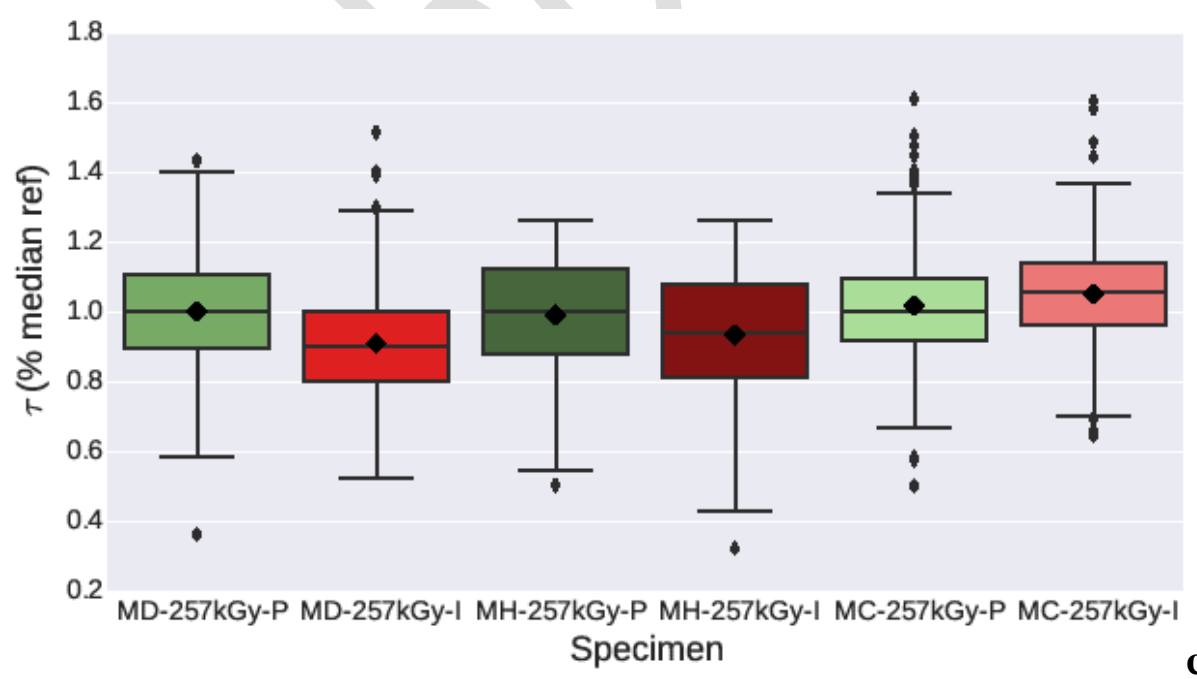

Fig. 14. Standardized creep parameters of the mortar specimens : (a) indentation hardness, (b)

377 indentation creep modulus, (c) indentation characteristic time. For each series, results were

378 standardized relatively to the median value of the unirradiated specimen (upper and lower 
379 lines of the box representing $1^{\text {st }}$ and $3^{\text {rd }}$ quartiles, the line inside the median value). Diamonds 380 represent mean values and external bars $1^{\text {st }}$ and $9^{\text {th }}$ decile.

\section{Summary and Conclusions}

The main objective of the present work was to accurately understand the alterations of mechanical properties of cementitious materials under low doses of gamma irradiations. This work is motivated by the increasing concern about the durability of nuclear wastes storage facilities which will withstand similar exposure conditions. Thus, three different mortar (dry, humid and carbonated) and two different cement pastes (dried and carbonated) were used.

Mechanicals properties were measured for each sample after an irradiation of $287 \mathrm{kGy}$ for mortars and 85,7 kGy for cement pastes. The results can be summarized as follows :

- Significant differences between pristine and irradiated cementitious materials have been observed at doses which are largely lower than up-to-date reported thresholds around $2.10^{5} \mathrm{kGy}[3][5]$,

- For the first time, a significant decrease of the compressive and bending strength for humid and dried mortar can be accurately measured, and mechanical properties of corresponding the cement paste should decrease too although dispersion of data does not lead to any statistical difference,

- Mechanical decreases are greater for dried mortar than humid mortar. Water seems to have an effect against mechanical deteriorations under gamma radiation. Thus water radiolysis may not play a leading role in the degradation phenomenon at small doses,

- Carbonated mortars were not affected after $275 \mathrm{kGy}$ gamma exposure. Gamma radiations have no effects on calcite phase. Given that the sand used to prepare the mortar is a $99.9 \%$ calcareous sand, we can then assume that the gamma radiation has 
mainly an effect on the cement paste phase. Nevertheless, a gamma irradiation study on pure calcite phase is required to confirm these observations,

- No modification of the total porosity was observed. However, the repartition of the porosity changes for humid and dried mortar indicating an evolution of the macroporosity toward the nanoporosity and there is a correlation between the decrease of the median pore diameter and the decrease of the compressive strength,

- Micro-indentation results, which are influenced by the local porosity, correlate well with these macroscopic observations concerning the porosity evolution,

- No modification of the chemical composition was noticed. Presently, only the variation of porosity can explain the decrease of the bending and compressive strength.

There is an untapped opportunity to understand the phenomenon at the origin of these mechanical modifications. Because gamma radiation seems to have a major effect on cement paste, mainly composed by calcium silicate hydrates $(\mathrm{C}-\mathrm{S}-\mathrm{H})$, future investigations will be carried out to study mechanical modifications under gamma radiation at a smaller scale.

\section{Acknowledgment}

We are thankful to l'Agence nationale de la recherche (French national research agency) for the financial support of the project. We would like to express our thanks to ARRONAX facility for gamma irradiation experiments. Also, we are grateful to Guillaume Blain for his assistance with the irradiation experiments.

\section{$\underline{\text { References }}$}

[1] J. Kot'átková, J. Zatloukal, P. Reiterman, K. Kolář, Concrete and cement composites used for radioactive waste deposition, J. Environ. Radioact. 178-179 (2017) 147-155. doi:10.1016/j.jenvrad.2017.08.012. 
[2] F. Bart, C. Cau-di-Coumes, F. Frizon, S. Lorente, Cement-Based Materials for Nuclear Waste Storage, 1st ed., Springer-Verlag New York, New-York, 2013.

[3] H. Hilsdorf, J. Kropp, H. Koch, The Effects of Nuclear Radiation on Materials Properties of Concrete, ACI SP 55. (1978) 223-251.

[4] Y. Le Pape, Structural effects of radiation-induced volumetric expansion on unreinforced concrete biological shields, Nucl. Eng. Des. 295 (2015) 534-548. doi:10.1016/j.nucengdes.2015.09.018.

[5] O. Kontani, S. Sawada, M. Takizawa, O. Sato, Evaluation of irradiation effects on concrete structure - Gamma-ray irradiation tests on cement paste, Proc. ASME 2013 Power Conf. (2013) 1-8. doi:10.1115/POWER2013-98099.

[6] K.G. Field, I. Remec, Y. Le Pape, Radiation effects in concrete for nuclear power plants - Part I: Quantification of radiation exposure and radiation effects, Nucl. Eng. Des. 282 (2015) 126-143. doi:10.1016/j.nucengdes.2014.10.003.

[7] I. Maruyama, O. Kontani, A. Ishizawa, M. Takizawa, O. Sato, Development of System for Evaluating Concrete Strength Deterioration Due to Radiation and Resultant Heat, Non-Metallic Mater. Ageing Manag. (2016) 3-6.

[8] A. Giorla, M. Vaitova, Y. Le Pape, P. Stemberk, Meso-scale modeling of irradiated concrete in test reactor, Nucl. Eng. Des. 295 (2015) 59-73. doi:10.1016/j.nucengdes.2015.08.027.

[9] T.M. Rosseel, K.G. Field, Y. Le Pape, D.J. Nauss, I. Remec, J.T. Busby, Dommages d'irradiation dans les cavités en béton des réacteurs aux Etats-Unis, Rev. Générale Nucléaire. 1 (2015) 21-27.

[10] Y. Le Pape, K.G. Field, I. Remec, Radiation effects in concrete for nuclear power plants, Part II: Perspective from micromechanical modeling, Nucl. Eng. Des. 282 (2015) 144-157. doi:10.1016/j.nucengdes.2014.10.014. 
[11] P. Soo, L.M. Milian, The effect of gamma radiation on the strength of Portland cement mortars, J. Mater. Sci. Lett. 20 (2001) 1345-1348.

[12] F. Vodák, K. Trtík, V. Sopko, O. Kapičková, P. Demo, Effect of $\gamma$-irradiation on strength of concrete for nuclear-safety structures, Cem. Concr. Res. 35 (2005) 14471451. doi:10.1016/j.cemconres.2004.10.016.

[13] B.G. Ershov, A. V. Gordeev, A model for radiolysis of water and aqueous solutions of H2, H2O2 and O2, Radiat. Phys. Chem. 77 (2008) 928-935. doi:10.1016/j.radphyschem.2007.12.005.

[14] E.M. Gartner, J.F. Young, D.A. Damidot, I. Jawed, Hydration of portland cement, in: Struct. Perform. Cem. Second Ed., Spon press, London, 2002: pp. 57-112.

[15] P. Bouniol, E. Bjergbakke, A comprehensive model to describe radiolytic processes in cement medium, J. Nucl. Mater. 372 (2008) 1-15. doi:10.1016/j.jnucmat.2006.10.004.

[16] P. Bouniol, Water radiolysis in cement-based materials, in: Radiat. Chem. from Basics to Appl. Mater. Life Sci., 2008: pp. 117-129. https://books.google.co.uk/books?id=hcfbMzy3kAcC.

[17] B. Tilquin, Actions Biologique et Chimique des Rayonnements Ionisants, Frison-Roc, Paris, 2002.

[18] G.W. Groves, D.I. Rodway, I.G. Richardson, The carbonation of hardened cement pastes, Adv. Cem. Res. 11 (1990) 117-125.

[19] K. Kobayashi, K. Suzuki, Y. Uno, Carbonation of concrete structures and decomposition of CSH, Cem. Concr. Res. 24 (1994) 55-61. doi:10.1016/00088846(94)90082-5.

[20] S.E. Pihlajavaara, Some results of the effect of carbonation on the porosity and pore size distribution of cement paste, Matériaux Constr. (1968). doi:10.1007/BF02473640.

[21] Yves F. Houst, Folker H. Wittmann, Depth profiles of carbonates formed during 
natural carbonation, Cem. Concr. Res. 32 (2002) 1923-1930. doi:10.1016/S00088846(02)00908-0.

[22] A.N.M. Bagyo, W.A. Lindu, S. Sadjirun, E.K. Winarno, E. Widayat, Aryanti, H. Winarno, Radiation Induced Degradation of Organic Pollutants in Waters and Wastewaters, 1995. doi:10.1017/CBO9781107415324.004.

[23] AFNOR, Essai pour béton durci - Essai de carbonatation accélérée - Mesure de l'épaisseur de béton carbonaté, XP P18-458 (2008).

[24] H. Fricke, E.J. Hart, Chemical Dosimetry, Radiation Dosimetry, New York, 1966.

[25] AFNOR, Béton - Essai pour béton durci - Essai de porosité et de masse Volumique, NF P18-459 (2010).

[26] R.A. Cook, K.C. Hover, Mercury porosimetry of hardened cement pastes, Cem. Concr. Res. 29 (1999) 933-943. doi:10.1016/S0008-8846(99)00083-6.

[27] B. Hilloulin, M. Robira, A. Loukili, Coupling statistical indentation and microscopy to reduce uncertainties identifying phases mechanical properties: application on $\gamma$ irradiated mortars, Submitted. (n.d.).

[28] N. Mobasher, S.A. Bernal, H. Kinoshita, C.A. Sharrad, J.L. Provis, Gamma irradiation resistance of an early age slag-blended cement matrix for nuclear waste encapsulation, J. Mater. Res. 30 (2015) 1563-1571. doi:10.1557/jmr.2014.404.

[29] J. Handin, D. V. Higgs, D.R. Lewis, P.K. Weyl, Effects of gamma radiation on the experimental deformation of calcite and certain rocks, Bull. Geol. Soc. Am. 68 (1957) 1203-1224. doi:10.1130/0016-7606(1957)68[1203:EOGROT]2.0.CO;2.

[30] Z. Kabacińska, L. Yate, M. Wencka, R. Krzyminiewski, K. Tadyszak, E. Coy, Nanoscale Effects of Radiation (UV, X-ray, and $\gamma$ ) on Calcite Surfaces: Implications for its Mechanical and Physico-Chemical Properties, J. Phys. Chem. C. 121 (2017) 13357-13369. doi:10.1021/acs.jpcc.7b03581. 
505 [31] E.P. Kearsley, P.J. Wainwright, The effect of porosity on the strength of foamed concrete, Cem. Concr. Res. 32 (2002) 233-239.

507

508

509

510

511

512

513

514

[32] X. Chen, S. Wu, J. Zhou, Influence of porosity on compressive and tensile strength of cement mortar, Constr. Build. Mater. 40 (2013) 869-874. doi:10.1016/j.conbuildmat.2012.11.072.

[33] D.P.H. Hasselman, Relation Between Effects of Porosity on Strength and on Young's Modulus of Elasticity of Polycrystalline Materials, J. Am. Ceram. Soc. 46 (1963) 564565. doi:10.1111/j.1151-2916.1963.tb14615.x. 